This item was submitted to Loughborough's Research Repository by the author.

Items in Figshare are protected by copyright, with all rights reserved, unless otherwise indicated.

\title{
A policy-level perspective to tackle rural digital inclusion
}

PLEASE CITE THE PUBLISHED VERSION

https://doi.org/10.1108/ITP-01-2020-0047

PUBLISHER

Emerald Publishing Limited

VERSION

AM (Accepted Manuscript)

\section{PUBLISHER STATEMENT}

This paper was accepted for publication in the journal Information Technology and People and the definitive published version is available at https://doi.org/10.1108/ITP-01-2020-0047. This author accepted manuscript is deposited under a Creative Commons Attribution Non-commercial 4.0 International (CC BY-NC) licence. This means that anyone may distribute, adapt, and build upon the work for non-commercial purposes, subject to full attribution. If you wish to use this manuscript for commercial purposes, please contact permissions@emerald.com.

\section{LICENCE}

CC BY-NC 4.0

\section{REPOSITORY RECORD}

Wagg, Sharon, and Boyka Simeonova. 2021. "A Policy-level Perspective to Tackle Rural Digital Inclusion". Loughborough University. https://hdl.handle.net/2134/16652086.v1. 


\section{EEmerald $\begin{aligned} & \text { Information Technology } \\ & \text { \& People }\end{aligned}$}

\section{A policy-level perspective to tackle rural digital inclusion}

\begin{tabular}{|r|l|}
\hline Journal: & Information Technology \& People \\
\hline Manuscript ID & ITP-01-2020-0047.R2 \\
\hline Manuscript Type: & Article \\
\hline Keywords: & $\begin{array}{l}\text { Digital divide < Phenomenon, Activity theory < Theory, Digital } \\
\text { intervention < Phenomenon, E-inclusion / exclusion < Phenomenon, } \\
\text { Disruptive technology < Technology, Government policy < Phenomenon }\end{array}$ \\
\hline \multicolumn{2}{|l}{} \\
\hline
\end{tabular}




\title{
A policy-level perspective to tackle rural digital inclusion
}

\begin{abstract}
Purpose - This paper explores how policy-level stakeholders tackle digital inclusion in the context of UK rural communities.

Design/methodology/approach - Semi-structured interviews were conducted with stakeholders that operate nationally in government departments, government funded organisations, and third sector organisations, that provided a policy-level perspective on digital inclusion initiative provision across England, Scotland and Wales. Activity Theory (AT) was utilised as a theoretical framework, where a variety of factors - tools, rules, community, division of labour, and contradictions - were found to have an influence on digital inclusion initiative provision.
\end{abstract}

Findings - Digital inclusion initiative provision in UK rural communities is organised through the multi-stakeholder involvement of national organisations, and collaboration with intermediary organisations to provide digital skills training and support. The process is fraught with difficulties and contradictions, limited knowledge sharing; reduced or poor-quality connectivity; lack of funding; lack of local resources; assumptions that organisations will indeed collaborate; and assumptions that intermediary organisations have staff with the necessary skills and confidence to provide digital skills training and support within the rural context.

Research limitations/implications - This study highlights the benefit of using AT as a lens to develop a nuanced understanding of how policy-level stakeholders tackle digital inclusion.

Practical implications -This study can inform policy decisions on digital inclusion initiative provision suitable for rural communities.

Originality/value -The contribution of this paper provides: new insights into the understanding of how policy-level stakeholders tackle digital inclusion and the provision of digital inclusion initiatives; it builds on the use of AT to help unpick the complexity of digital inclusion initiative provision as a phenomenon; it reveals contradictions in relation to trust, and the need for knowledge sharing mechanisms to span and align different interpretations of digital inclusion across the policy-level; and reveals an extension of AT demonstrated through the 'granularity of the subject' which enables the multi-actor involvement of the stakeholders involved in digital inclusion at policy-level to emerge.

Keywords Digital inclusion, activity theory, rural, policy-level 


\section{Paper type Research paper}

\section{Introduction}

Despite the increased ubiquity of digital technologies in almost every aspect of working and existing, access to and the use of technologies remains unequal and problematic. The multitude of factors which contribute to digital exclusion are complex, making the task of implementing workable digital inclusion initiatives challenging for policymakers (Bach et al., 2013) especially for rural communities (Williams et al., 2016; Philip and Williams, 2019), due to the variability in access to and distribution of technological infrastructure, technological capabilities, but also issues in terms of both culture and process (Jussila et al., 2019; Philip and Williams, 2019).

In the UK, the last few years have seen a significant bolstering of the national digital inclusion agenda, following the release of the government digital strategy (Cabinet Office, 2013), resulting in a growth of digital inclusion initiatives designed to provide opportunities to accessing and using digital technologies in the effort to reduce digital inequalities in local communities (Mervyn et al., 2014; Wagg et al., 2018). Indeed, as identified by scholars, digital inclusion has been pushed as a priority issue by policymakers around the world (Díaz Andrade and Techatassanasoontorn, 2021), yet, not all digital inclusion initiatives have proven successful (Madon et al., 2009; Helsper and Reisdorf, 2017; Beattie-Smith, 2013; Hamburg and Lütgen, 2019; Davies et al., 2017). This therefore raises questions about the current policy discourse of digital inclusion initiatives.

Scholars highlight that while efforts in improving access and technological infrastructure are increasing, access to Information Communication Technologies (ICT) cannot rest on providing devices or conduits alone, emphasising that policymakers should take into account the social, cultural, economic and geographical context of where these initiatives are implemented (Correa and Pavez., 2016; Salemink et al., 2017), and the digital skills of individuals and social support available (Courtois and Verdegem, 2016; Asmar et al., 2020). However public-policy discourse regarding the problem of digital inequalities continues to fall short of reflecting the complex realities of digitally excluded communities (Gordo, 2015; Mariën and Prodnik, 2014), often assuming a simplistic notion that nonusers lack the interest and skills to capitalize on digital resources (Gordo, 2015). 
As stated by Hepburn (2018), the problem of digital exclusion has still not been adequately resolved and commentators worry that pushing on with ambitious digital policy agendas (such as Digital-by-Default - replacement of services delivered through in person, telephone and paper-based interactions, with online services) will exacerbate existing inequality of access to digital services. Indeed the UK's House of Common's (2019) recent report “An Update on Rural Connectivity" supports Hepburn's concern claiming that delivering a Digital-by-Default strategy for public services, before solving the issue of poor connectivity in rural areas, has worsened the impact of the digital divide, stating that $40 \%$ of UK rural areas have poor Internet connectivity. Hepburn (2018) argues that this failure to tackle digital exclusion appears symptomatic of both central and local government inability to efficiently implement the digital policy agenda.

Scholars argue that digital inclusion policies continue to struggle to address significant inequality issues, due to the incorporation of narrowly conceived, short-term, technologycentric solutions (Mariën and Prodnik, 2014; Díaz Andrade and Techatassanasoontorn, 2021). Indeed, research that does exist appears fragmented (Wagg et al., 2020), and predominantly focused on the recipients of digital inclusion initiatives at individual level (López et al., 2018), with little understanding from a policy-level perspective, or policy-level stakeholders. Mervyn et al. (2014) state that the limited scope and robustness of empirical research in the digital inclusion realm, "restricts policymakers' ability to devise and implement social strategies and activities" (p.1100). In addition, Mariën and Van Audenhove (2012), explain that a more comprehensive understanding of digital inclusion is required to understand issues which "hamper the realisation of sustainable digital inclusion" (p.6). The current need to research these issues is ever more urgent as scholars highlight the need to challenge the current status quo dominated in "policy and scholarly discourses on digital inclusion and the stigmatisation of Internet non-users" (Díaz Andrade and Techatassanasoontorn, 2021, p.185).

Hence the need for research that explores digital inclusion from a policy-level perspective through the insights of policy-level stakeholders that tackle digital inclusion. This paper therefore extends existing literature by developing a critical discussion through the insights of digital inclusion stakeholders that operate nationally at policy-level. These stakeholders are from national organisations whose involvement operating within the digital inclusion realm ranges from contributing to policy development and parliamentary committees; translating digital policy, and national digital inclusion policies and strategies in practice; to creating 
digital policy. As such, policy-level stakeholders possess a variety of experiences, from the narrow involvement of stakeholders from government organisations to the involvement of stakeholders in third sector organisations.

Furthermore, scholars have identified a lack of literature which explores digital inclusion through a theoretical lens (Wagg et al., 2020; Al-Muwil et al., 2019), which could be argued is somewhat surprising considering the complexity of digital inclusion. The authors of this paper argue the use of theory is required to guide digital inclusion research and recommend the use of Activity Theory (AT). The aim of this paper is to provide understanding of how policy-level stakeholders tackle digital inclusion, in the context of UK rural communities, through the utilisation of AT. The paper posits the following research questions: How do policy-level stakeholders tackle digital inclusion and digital inclusion initiative provision? What are the challenges of digital inclusion initiative provision and how could these challenges be resolved?

The contributions of this paper include: i) new insights into the understanding of how policylevel stakeholders tackle digital inclusion and the provision of digital inclusion initiatives in UK rural communities; ii) the use of AT to help unpick the complexity of digital inclusion initiative provision as a phenomenon; iii) the contradictions within the policy-level activity system, specifically in relation to trust, and the need for knowledge sharing mechanisms to help understand and align differing interpretations of digital inclusion across the policy-level; and iv) an extension of AT demonstrated through the 'granularity of the subject' which enables the multi-actor involvement of the stakeholders involved in digital inclusion at policy-level to emerge.

Importantly this paper challenges the status quo that is dominated by studies on Internet users and digital inclusion by providing a more critical perspective on digital inclusion initiative provision, so often overemphasised as the solution to digital divide problems and the policy rhetoric in which they are framed. As such this paper reveals opportunities for change in the provision of digital inclusion initiatives that have implications for policy and practice.

The remainder of the paper is organised as following: the next section outlines a review of relevant literature, including the concept of digital inclusion and recent research on digital inclusion initiatives. This is followed by an outline of AT and a description of the research methodology used. The next sections present the analysis from the study, a discussion of findings, conclusion and future research. 


\section{Literature Review}

\section{Digital Inclusion}

Digital inclusion literature historically has been dominated by research on digital divide and digital inequalities (Van Dijk, 2005; Helsper, 2017). More recently, digital inclusion literature has recognised the high degree of correlation between digital inequalities and social exclusion (Mervyn et al., 2014; Helsper, 2008); the strong link between socioeconomic exclusion and digital exclusion (Clayton and Macdonald, 2013; Buchanan et al., 2018), and identified the need of a more nuanced understanding of digital exclusion (Mariën and Prodnik, 2014; Helsper and Reisdorf, 2017; Zheng and Walsham, 2008).

Digital inclusion refers to the activities necessary to ensure that all individuals and communities, including the most disadvantaged, have the right access, motivation, skills and trust to navigate confidently online and access opportunities on the Internet (Government Digital Service, 2014). Digital inclusion activities essentially include: i) affordable, and good quality broadband and mobile access, ii) Internet-enabled devices, iii) quality technical support, iv) accessible applications and online content designed to enable and encourage selfsufficiency, participation, and collaboration, and v) access to digital skills training and support (Park et al., 2019; Al-Muwil et al., 2019, Fang et al., 2019). Such digital inclusion activities are delivered through the provision of initiatives by a plethora of organisations (public, private and third sector), to tackle digital inequalities, the implementation of Digital-by-Default, and improve social inclusion, (Mariën and Van Audenhove, 2012; Al-Muwil et al., 2019; Yates et al., 2015).

However, digital inclusion suffers from conceptual inconsistencies and dichotomies that lead to ambiguities in understanding why and what is needed to be included in the information society (Nemer, 2015; Jaeger et al., 2012). According to Helsper (2008), digital inclusion should be conceptualised around issues of: digital access, motivation, knowledge, and skills. Borg et al., (2018) identify key enablers to digital inclusion: (i) social support (ii) education via collaborative learning or direct experience and (ii) inclusive design. In addition, Bradbrook and Fisher (2004) highlight content, connectivity (access), confidence (self-efficacy), capability (skill), and continuity (of usage) as important aspects of digital inclusion. Hache and Cullen (2009) extend the definition by arguing that digital inclusion is the process of democratisation of access to ICT in order to allow for the inclusion of marginalised groups in society, thus adding to ongoing scholarly debate of the correlation between digital inclusion 
and social inclusion and whether the former (digital inclusion) leads to the latter (social inclusion) (Meryvn et al., 2014; Taylor and Packham, 2016; Buré, 2006).

Despite the bolstering of digital inclusion initiatives there continues to be a myriad of reasons as to why people are not digital and Internet users. Key barriers to digital inclusion identified are the lack of motivation, insufficient digital skills, scarce resources and support, limited opportunities regarding training, learning or usage; and cost (Helsper 2012; Mariën and Van Audenhove, 2011; Borg et al., 2018; Tsatsou, 2019; El-Haddadeh et al., 2019; Mahmood et al., 2018).

In addition, there are ongoing challenges in relation to trust with the Internet particularly in relation to government online services (Al-Muwil et al., 2019); the usability of online services introduced through Digital-by-Default (Yates et al., 2015; Damodaran et al., 2015); but also where they can access these services in public venues (Gomez and Gould, 2010). Indeed, as highlighted by Helsper (2008) and Mariën and Prodnik (2014), the obligatory use of ICT through Digital-by-Default, is creating mechanisms of user disempowerment and limiting individual ability to make free digital choices. Hence while debate on digital inequalities has created substantial knowledge about the individual digital capabilities, motivations, and barriers, there is a need to expand the debate from this micro/individual-level perspective to a policy-level perspective to understand the determinants and influences in policy which impact digital inclusion initiative provision (Gordo, 2015; Mariën, 2016; Iordache et al., 2017). Indeed, research at policy-level appears scarce.

Exceptions include research by Polat (2012) that explores digital exclusion in Turkey, and research by Aziz (2020) on challenges of digital inclusion in Bangladesh. Polat (2012) for example, argues that techno-centric digital inclusion solutions, which fail to address the most disadvantaged groups, currently occupy the digital inclusion policy agenda, at the expense of more sophisticated programs that take into account the social context of digital exclusion. Research by Aziz (2020), whilst in a different context agrees with this argument, highlighting how techno-centric policy has a narrow frame of reference, that does not comprehensively address the issues associated with digital inclusion. However, both these studies took a policy perspective through the analysis of policy documents opposed to the perspectives of the policylevel stakeholders who could provide a richer account of how they tackle digital inclusion and digital inclusion initiative provision. A review of recent research on digital inclusion initiatives follows. 


\section{Digital inclusion initiatives}

The digital inclusion initiatives need to help to enable individuals to participate actively in society, to access digital services, products and networks, and support better economic, health and social outcomes for those on the wrong side of the digital divide (Bach, et al., 2013; Díaz Andrade and Doolin, 2019). While many digital inclusion initiatives have achieved success (Mariën and Van Audenhove, 2012; Taylor and Packham, 2016), others have reported incidences of failure. For example, Correa and Pavaz (2016) discuss digital inclusion initiatives in Latin America targeting rural areas. Their research confirmed that most of these policymaking initiatives focused on the provision of infrastructure; yet while access to both devices and infrastructure connection cannot be dismissed as a logical initial step, it does not necessarily entail Internet adoption, particularly in isolated, rural contexts. Hence policymakers should take into account the social, cultural, and economic context of where these initiatives are implemented (Correa and Pavaz, 2016). In addition, Helsper and Reisdorf (2017) highlight that the factors why people disengage with the Internet need to be understood if successful digital inclusion interventions are to be provided. For example, analysis of data collected from Scottish Citizens Advice Bureau clientele revealed that users who were least proficient in digital skills were also the least likely to take advantage of training opportunities (BeattieSmith, 2013).

Meryvn et al. (2014) investigated two contrasting digital inclusion initiatives by local government which provided access to local online support and services. The first of the two initiatives advocated a bottom-up infrastructure-based model, with non-state involvement that focussed primarily on achieving the provision of physical access to the Internet. Whereas the second initiative took a much more proactive and centrally planned approach to service provision with the use of intermediaries. A key finding was that while both these approaches succeed to some extent, initiatives are much more likely to succeed if they are "part of a process of supporting existing intermediaries" (Meryvn et al., 2014, p.1098). Indeed Damodaran et al. (2015) research on sustaining ICT use by older people highlighted the inadequacy of support and the need for readily available on-going ICT support within the community for digital inclusion initiatives.

Other research emphasises the need for digital inclusion initiatives to use participatory approaches in community-based organisations (Gangadharan, 2017; Mariën and Van Audenhove, 2012; Taylor and Packham, 2016) and non-organisational contexts (Gripenberg, 
2011), for individuals and communities to learn digital skills and improve computer selfefficacy. Other scholars have noted the value of using an asset-based approach to digital inclusion, which "seeks out community anchor institutions as the locus of existing capacitybuilding and community-development efforts" (Reisdorf and Rhinesmith, 2018, p.43).

\section{UK rural digital inclusion initiatives}

Research exists examining the issues of the rural digital divide, and rural broadband within the UK context (Ashmore et al., 2015; Philip et al., 2017; Roberts et al., 2017a, Roberts et al., 2017b; Salemink et al., 2017; Williams et al., 2016; Gerli et al., 2020), where a rural digital divide remains (Philip et al., 2017; Salemink et al., 2017). Indeed, scholars highlight how despite the diffusion of broadband initiatives, such as the Broadband Delivery UK, a proportion of the rural population in the UK are still unable to connect to broadband and $4 \mathrm{G}$ mobile networks (Ashmore et al., 2015; Philip et al., 2017; Gerli et al., 2018; Philip and Williams, 2019). Some scholars attribute this to problems regarding the provision of broadband infrastructure, which due to the rurality of some locations are 'economically unattractive to the private companies that characterise today's telecommunications industry' (Gerli et al., 2020, p.540). Others attribute this to the poor quality or intermittent connectivity provided in rural communities (Williams et al., 2016; Gann, 2019).

What is evident from research on rural digital inclusion initiatives is its focus on digital connectivity and the broadband availability (Cowie et al., 2020). In contrast there appears to be limited research with a focus on digital inclusion training and support as part of digital inclusion initiatives, particularly within the context of UK rural communities. Exceptions include studies by Huggins and Izushi (2002) and Faulkner and Kleif (2005) which while premobile and broadband connectivity and pre-Digital-by-Default, highlight issues that are just as relevant today for UK rural communities. For example, Huggins and Izushi (2002) review of digital inclusion initiatives in rural counties across the UK identifies criteria for digital inclusion good practice. These include use of community resource centres; targeting of personal and cultural activities that fit into the community; support for self-managed learning; mobile provision of training programmes (training beyond fixed locations to support the 'transport-poor'); demonstrations of the benefits of digital through the use of in general services; and financial support due to the additional costs incurred through delivering training in rural locations, often referred to as the 'rural premium'. 
More recent UK studies include an evaluation of two rural community broadband initiatives: Connecting Cumbria and Broadband for the Rural North (Gerli et al., 2018). The main focus of their research was on broadband with the mention of training and workshops to help the adoption of the Internet.

\section{Digital inclusion rhetoric in UK rural communities}

Scholars highlight there is an urgent need for online services to be accessible by those residing and working in rural areas (Williams et al., 2016). Indeed, Philip and Williams (2019a) state how "paradoxically ICTs continue to be championed in policy and regional development as ways in which the relative disadvantages of rurality can be overcome" (p.620). Yet UK rural areas continue to suffer from the uneven distribution of digital and technological infrastructure through market-driven approaches, leaving rural communities unable to exploit the full potential of the Internet and digital technology (Philip et al., 2017; Roberts et al., 2017a). This issue is further exacerbated by policy and digital inclusion initiatives which as stated by Salemink et al. (2017) have been "criticised for ignoring the rural socioeconomic and geographical contexts, resulting in generic initiatives with limited effects on the adoption and use of ICTs by the most vulnerable groups in rural and remote areas" (p.366). Indeed, the literature review conducted by Salemink et al. (2017), includes a small section on policy studies on digital inclusion that provide insights from using a macro-level and agenda-setting approach to digital inclusion, or from a micro-level approach, evaluating specific initiatives and methods designed to promote inclusion of specific groups. However, none of the papers cited are from the perspective of the stakeholders operating at policy-level, highlighting an important research gap.

While it is important to acknowledge the benefits of digital inclusion initiatives on communities, there is a notable lack of critical perspectives at policy-level and the advocates of digital inclusion programmes (Eubanks, 2011; Mori, 2011) and by some scholars (Ragnedda, 2018). For example, the ongoing rhetoric emphasised largely through European social policy for the need to remedy social exclusion through digital inclusion, appears to put the responsibility on individuals and communities lacking skills rather than on structural or societal problems (Taylor and Packham, 2016), which in turn as stated by Roberts et al. (2017a) "removes both responsibility and accountability from the state to the individual when something goes wrong” (p.380). Klecun (2008) calls into question current discourse and initiatives tackling the digital divide and the current limitations, asserting that people should 
be allowed to make an informed choice concerning joining or declining to join the digital society.

To increase our understanding of digital inclusion initiatives, and how policy-level stakeholders tackle digital inclusion, the utilisation of Activity Theory (AT) helps to answer the research questions posited earlier.

\section{Activity Theory}

AT provides a sociocultural theoretical framework that provides a lens through which to understand mediated actions within an activity system (Leontev, 1978; Vygotsky, 1978). It also provides a language for understanding complex real-world activities situated in cultural and historical contexts (Engeström, 1987).

What sets AT apart from other theories is its ability to "dialectically link the individual and social structure" (Engeström, 1999, p.19). Indeed, Engeström (1999) highlighted the need to have an approach to resolve dualisms which exist between macro and micro, individual and society, structural and agency and other dualisms in social theory. Digital inclusion suffers with associated dualisms such as digital inclusion/digital exclusion and its relationship with the digital divide. AT is therefore particularly suitable for unpicking and developing a nuanced understanding of digital inclusion initiatives and the interrelationships between digital inclusion stakeholders while taking into account the environment, culture, motivations and complexity of real settings.

The AT aspect of mediation of human behaviour through tools and technologies, its ability to provide structural and individual level explanations, and extracting contradictions from an activity system, are key strengths which scholars have drawn upon when using AT in digital inclusion research. For example, Mervyn et al. (2014) used AT to provide a theoretical and analytical framework to problematise and study the inter-organisation of digital inclusion initiative provision. Their research specifically examined two contrasting UK local government digital inclusion initiatives which provided access to local online support and services. Aires (2014) used AT to explore the opinions of parents and teachers on the Magellan digital inclusion initiative in Portugal, to investigate common understandings and contradictions in the dissemination of digital technologies and digital inclusion in families and schools in rural communities. In both instances, these studies specifically draw on the AT principles of multiple perspectives and contradictions and highlight how AT enables a multi-perspective analysis of 
stakeholders involved in the implementation, provision and social support of digital inclusion initiatives. For example, using the elements of AT, Mervyn et al. (2014) identified the motivation and goals of each initiative, the higher-level object, the tools, the rules and norms, the division of labour, the community, the outcomes, the evaluative criteria to assess project success and the areas of contradiction. However, the application of AT in the field of digital inclusion appears relatively scarce.

Engeström (1999) describe the five AT principles which represent the underlying structure and dynamics of activity. These five principles are i) the activity system as a unit of analysis; ii) multiple and different perspectives; iii) historicity; iv) contradictions as a source of change and v) expansive transformation (Engeström and Sannino, 2010). The first principle - the activity system - is the unit of analysis, and as illustrated in Figure 1.

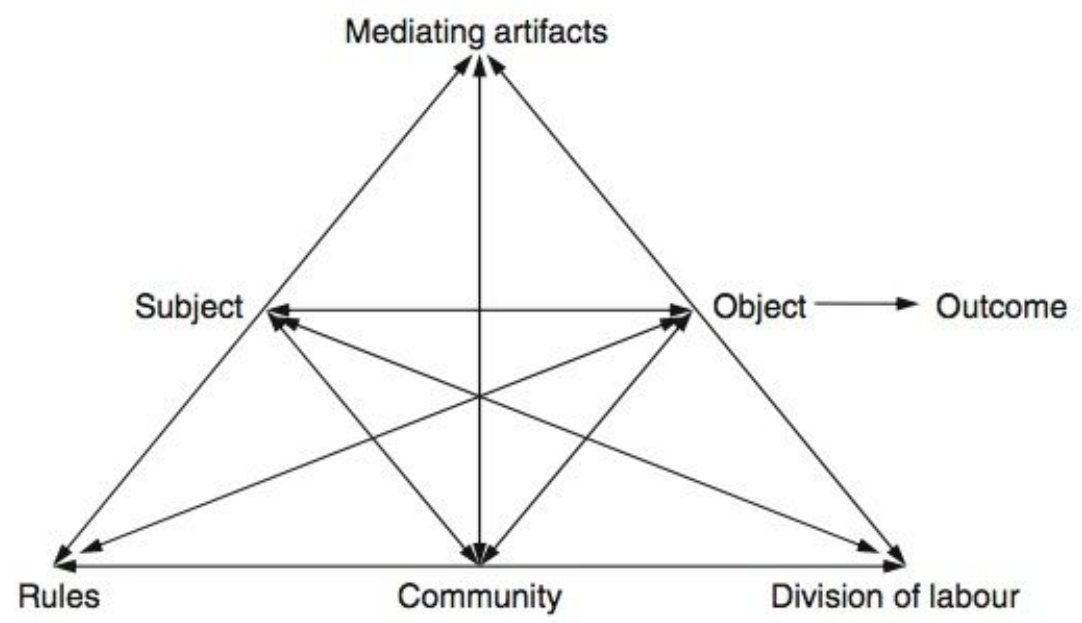

Figure 1: Second-generation Activity Theory (adapted from Engeström, 1999).

The unit of analysis is structured by six elements (subject, object, tools, rules, community and division of labour) that influence an activity. Subject is the individual or group whose position and viewpoint is adopted as the perspective of the analysis (Engeström and Sannino, 2010). In the context of digital inclusion this could be an individual or a collection of stakeholders involved in the provision of digital inclusion initiatives. Object (objective or goal) precedes and motivates activity. It refers to "the 'raw material' or 'problem space' at which the activity is directed, and which is moulded or transformed into outcomes with the help of physical and symbolic tools" (Engeström, 1993, p.67). An example of the object in the digital inclusion context could be the provision of digital inclusion initiatives. Tools mediate the object of activity and can enable or constrain activity. Mediated actions are activities that incorporate 
socially constructed tools to achieve a concrete or abstract goal. Tools themselves may be concrete (e.g. technology) or abstract (e.g. language) as well, and both actions and tools are shaped by the social, cultural, historical and institutional experiences of the community (Engeström, 1987). Common tools in the digital inclusion context include digital mobile devices, online learning tools, but also more abstract tools such as language. Community comprises of the individuals and subgroups who share the general object (Engeström and Sannino, 2010), such as local and regional organisations and digital champions that provide digital inclusion skills training and support. The division of labour refers to the division of power and status (Engeström and Sannino, 2010). Power aspects could also be manifested in other elements of AT (Simeonova, 2018). Rules are explicit and implicit norms that regulate actions and interactions within the system (Kuutti, 1996).

It is this conceptualization of the elements of the activity system which enables the possibility to understand different, even contradicting perspectives represented in one activity system or across a network of various activity systems. AT adopts the key notion that one cannot understand each element of an activity in isolation; rather, it posits that one can understand them only through interactions with the other elements.

The second principle of activity theory is multiple perspectives: the activity, for example, involves a collective of interacting individuals, communities, and organisations which express different interests and perspectives; therefore, in this case the perspectives of digital inclusion stakeholders operating nationally at policy-level.

The third principle emphasizes the historicity of activity as the activity system develops an understanding of its current form requires knowledge about its past, for example the development of UK digital inclusion policy.

The fourth principle focuses on the notion of contradictions within an activity. As contradictions arise, they expose the dynamics, inefficiencies and, importantly, opportunities for change within an activity (Helle, 2000). Contradictions are "historically accumulating structural tensions within and between activity systems" (Engeström, 2001, p.137), and Karanasios (2018) explains that "while the term contradiction may be considered by some as a weakness within an activity, it is in fact a sign of richness and the capacity of an activity to develop, rather than to function in a fixed and static mode" (p.140). Contradictions within the activity system can be revealed in four ways i) within the elements of an activity (e.g., tools, 
rules, subjects); ii) between elements of an activity (e.g., between a subject and a tool); iii) between a central activity at one point and more advanced form of the activity at a later point; and iv) between co-existing or neighbouring activities (Engeström, 1999; Karanasios and Allen, 2013).

The fifth principle refers to the possibility of expansive transformations or collective change of the activity as a result of these contradictions, for example, developing a new process or approach (Engeström, 2001). For example, the introduction of a new digital inclusion training tool and the implications for change this has on community engagement with learners.

The AT principles and elements (object, subject, tools, rules, community and division of labour) are useful for this study as can be used to conceptualise the research findings by providing a framework of the activity under investigation and reveal the interrelationships and dynamics that shape the activity. This in turn helps to unpick the complexity of how policy-level stakeholders tackle digital inclusion.

\section{Method}

The study utilizes a qualitative exploratory approach and reports on a policy-level investigation on how policy tackles digital inclusion within the context of UK rural communities. A qualitative approach was considered suitable for this study due to the need to look for "a complex, detailed understanding" of the issue under scrutiny (Cresswell, 2007, p.40), to provide richer, more flexible, context-orientated data to gain a better understanding of the real world (Mason, 2002) and to understand how people perceive and interpret events (Gorman and Clayton, 2005). Furthermore, AT can be used as an additional tool in qualitative approaches (Yamagata-Lynch, 2010), and provides a "holistic and contextual method of discovery that can be used to support qualitative research" (Hashim and Jones, 2007, p.1). The qualitative approach involved semi-structured interviews and a document review. Using this range of data collection methods enabled 'triangulation' (Bryman, 2012).

Relevant documents for the study were collected and reviewed during the data collection process to provide additional insight to data gathered through interviews. Specific documents reviewed included the UK's digital strategy and digital inclusion policies from national UK governments. From an AT perspective such documents or artefacts help gain an understanding about the rules and division of labour, but also about the community within an activity system. 
Semi-structured interviews with 20 individuals from national organisations were conducted in 2018-2019. Participant stakeholders included government officials, heads of service, policy leads, researchers and academics, from organisations such as government departments, government funded organisations, and third sector organisations. Participants were selected on their ability and position to share insights and understandings of digital inclusion within the UK and more specifically UK rural communities, and to provide a policy-level perspective on digital inclusion and digital inclusion initiative provision. A combination of purposeful and snowball sampling was used, to target and reach participants (Bryman, 2012; Miles et al., 2014). The sampling process continued until theoretical saturation was reached, where examination of additional data revealed no further themes (Eisenhardt, 1989). This rich sample was drawn from a relatively small group of stakeholders that specialise in digital inclusion across the UK that operate nationally at policy-level. Reference to "stakeholders" from now on in the paper refers to digital inclusion stakeholders that operate nationally. No repeat participants took part in the study and efforts were sought to ensure the representation of "a variety of voices" (Myers and Newman, 2007, p.22). For example, efforts were made to interview stakeholders from the different UK nations (England, Scotland and Wales, excluding Northern Ireland) to capture insight about the different policies in each nation, and from different sectors within those nations.

Interviews lasted between 30 and 90 minutes and all were audio recorded and transcribed. The interview questions were informed from the findings of the literature review, mapped at the AT elements and principles, and framed to get an understanding of digital inclusion initiatives within the UK and UK rural communities from a policy perspective. Questions were ordered in a manner that asked participants (subjects) to describe their historical and current knowledge of digital inclusion initiative provision and digital policy within the UK (object), to create digitally included communities (outcome). Subsequent questions explored specific aspects of digital inclusion initiatives such as the impact to beneficiaries of digital inclusion initiatives, the role of intermediaries and any challenges delivering digital inclusion activities, specifically in rural communities. Additional questions related to Tools, Rules, Communities, and the Division of labour, were also explored through the participants' experiences and perspectives. For example participants were asked about what resources were commonly used to deliver digital inclusion initiatives to reveal tools used such as digital devices. Participants were specifically asked about policy and the political environment and how these affect the provision of digital inclusion provision to reveal specific rules such as the UK digital strategy. 
Data collection and analysis of the interviews and document analysis was theory guided through the use of AT. Thematic Analysis (Braun and Clarke, 2006) was also employed to allow the data to 'speak'. The process of generating codes and themes involved the six phases of Thematic Analysis (Braun and Clarke, 2006), consisting of 1) data familiarisation, 2) generating initial codes, 3) searching for themes, 4) reviewing themes, 5) refining and naming themes to build a thematic network, and 6) reporting. At phase 5 an AT framework was employed to understand these themes and used to provide the theoretical elements around which the thematic network is created. Such use of AT is not unusual (Macpherson, 2006; Simeonova, 2014). When using AT as part of the analysis the following steps are followed. Through the lens of AT, the subject, object and the outcome should be identified. This is followed by the identification of the community, the tools, the rules, and the division of labour, to develop an activity system diagram and to identify inner contradictions within the developed activity system framework (Prenkert, 2006). Following these steps, a thematic network is developed, and presented in Appendix 1.

\section{Findings}

Analysis of the thematic network reveals the findings and produces a single activity system presented in Figure 2. Through the lens of AT, the findings highlight relationships across the activity system and within and between the AT elements and mediating factors. The findings from the activity system are described and contradictions which permeate the activity system are revealed.

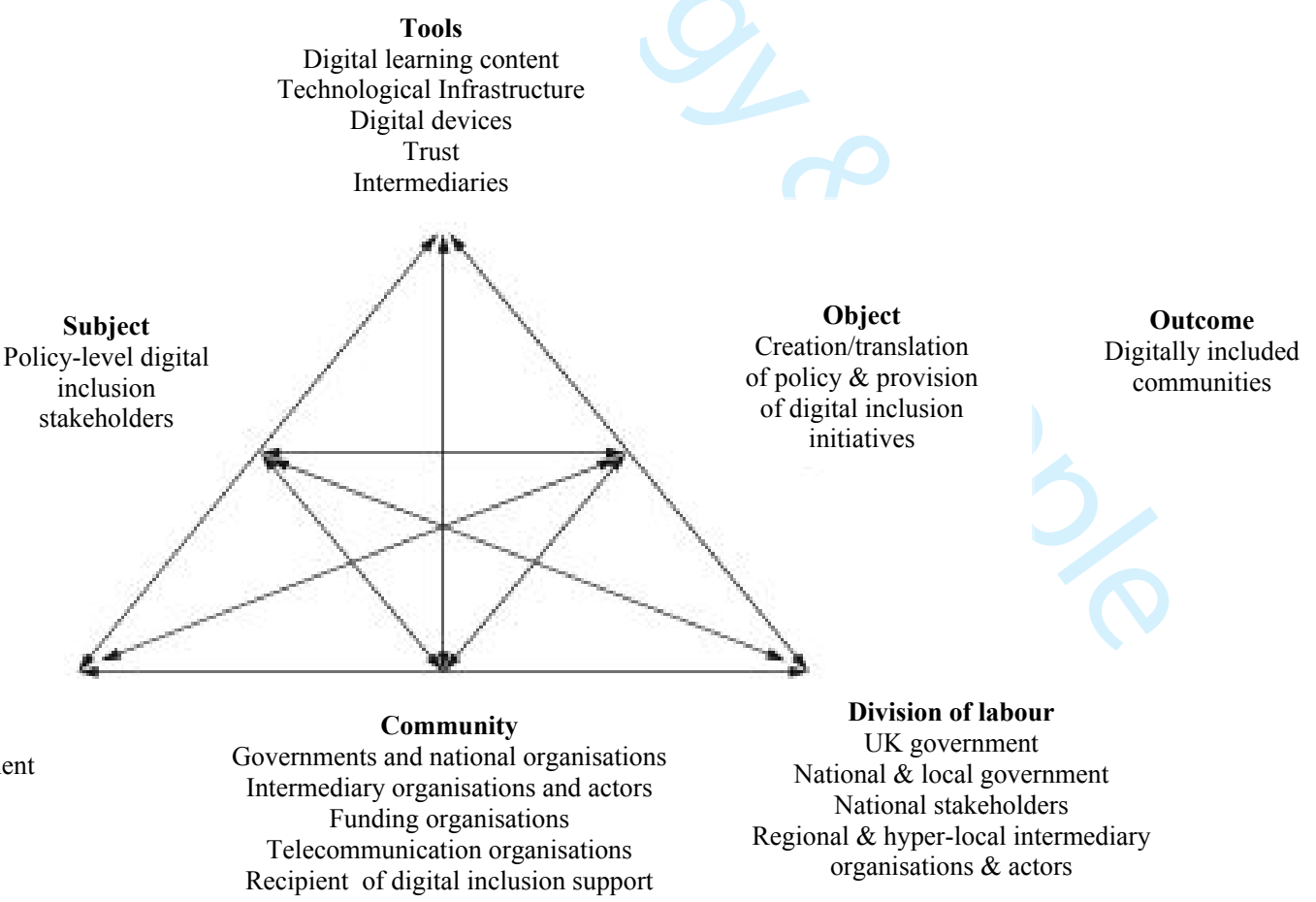


Figure 2: Policy-level digital inclusion activity system

The findings provide an understanding of the rapidly evolving UK digital inclusion landscape from a policy-level perspective, specifically in the context of UK rural communities. Policylevel stakeholders' (the subjects of the activity system) provided insight about their involvement in the digital inclusion realm and how they tackle digital inclusion through the provision of digital inclusion initiatives. This is illustrated through the activity system presented in Figure 2. which shows how stakeholders converge to act upon a shared problem and realise the object - creation/translation of policy and digital inclusion initiative provision (object), in the effort to achieve digitally included communities (outcome). While each individual that formed the subject could have its own activity system, or be grouped into several activity systems, the level of abstraction needs to be considered. It was therefore decided to develop a single activity system with the shared object of creation/translation of policy and digital inclusion initiative provision. Stakeholders were drawn from disparate organisations, including government departments, and national third sector and government funded organisations, who had contrasting organisational cultures, operational practices and social agendas. Stakeholders were therefore able to provide a multiple policy-level perspective on the digital inclusion landscape, not just because they were different entities, but also because they were from disparate organisations, and different UK nations (England, Scotland and Wales, excluding Northern Ireland). As such while broadly having the same shared object, findings reveal stakeholder organisations tackle digital inclusion in different ways and with different agendas. For example, stakeholders from national third sector and government funded organisations, had knowledge of digital inclusion provision in UK rural communities due to their close connections with community grassroot organisations delivering digital inclusion training and support. In comparison, government officials spoke more about digital inclusion provision in general UK terms, with relatively few references to UK rural communities. So, while the activity system has a shared object, it is clear there is tension in achieving that shared object, highlighting a granularity in the object and a tension within the subjects (as further discussed in the contradiction section of the paper).

Stakeholders agreed unanimously that digital exclusion and digitally marginalised communities continues to be a phenomenon in the UK and therefore an ongoing priority in the policy context. They concluded that the UK digital inclusion landscape has changed significantly over the past ten years, where the number of digitally excluded individuals while 
reducing year on year, has more recently stabilised, where the remaining digitally marginalised communities are the hardest to reach as highlighted:

"It's more about trying to help people who are more reluctant [to get online and use digital technology] and that's the latest challenge we've got" [Senior official within government funded organisation]

As a result, stakeholders have had to evolve and devise more innovative ways in how they translate digital inclusion policy and how they engage with digitally marginalized communities. Stakeholders indicated how there has been a movement away from traditional top-down approaches to digital inclusion initiative provision, to evolving more integrated approaches, that involve working in collaboration with regional and local community intermediary organisations who are able to reach and engage with digitally marginalised communities. AT allows us to demonstrate this integrated but evolving approach by illustrating the interactions and relationships among stakeholders and actors and the mediating activities within the activity system. For example, drawing on the AT principle of historicity, stakeholders provided a historical overview of the development of digital inclusion policy and the implications for digital inclusion initiative provision, specifically the multi-agency network of organisations involved in the implementation and provision of digital inclusion initiatives. Such organisations include those from third sector, government departments; and government funded organisations operating nationally at policy-level, through to intermediary organisations such as regional and local community partners, including local authorities, public libraries, social enterprises, charities, operating more at a regional or local-level. These organisations, in addition to funding organisations, private sector companies such as telecommunication organisations, through to the individuals who have received digital inclusion training and support, represent the community of the activity system, in which collaboration and an element of trust is assumed.

AT helps to reveal the various roles and level of involvement and hierarchy community members possess within this activity system through the division of labour element of the system to achieve the object. In broad terms, stakeholders described this division of labour in how UK government advises and encourages digital inclusion networks and organisations at policy, national, regional and local (grassroot) level to work collaboratively and in partnership to be able to reach out and engage with digitally excluded communities. These local and regional organisations play a key intermediary role in reaching out to those that are hard to 
reach and include paid and unpaid staff who operate as digital champions and/or digital training tutors, who deliver training within a shared space, where people already attend for other activities, such as book groups in a library or an advice centre; or in a space purposely used for training, such as a learning centre.

The division of labour between policy-level stakeholders (the subjects) revealed how they have taken on a variety of roles in an attempt to align with the evolving nature of digital inclusion provision. For example, some stakeholders work for organisations that create policy, others have presumed a more advisory/convening role in relation to policy development, while others take on more of a strategic role in the design and provision of digital inclusion initiatives, including the distribution of digital devices and development of learning materials. In some cases, organisations provide digital skills training for intermediary organisations, digital inclusion initiative evaluations, and distribute funding to digital inclusion intermediaries and actors working on a competitive basis. Stakeholders revealed how some organisations span these roles while others have a narrower involvement in digital inclusion. Indeed, in most cases digital inclusion is often one of many activities that organisations perform.

The actual mediating tools and artifacts used to tackle digital inclusion and the delivery of the provision of digital inclusion initiatives revealed by stakeholders was largely through the use of technological infrastructure (e.g. broadband and mobile connectivity) and devices (e.g. access to mobile devices, PCs, and laptops); digital skills learning content (online, offline and blended) and trust. However, it is the crucial involvement of intermediaries in the form of intermediary organisations such as public libraries, online centres, community centres and advice centres that operate at grassroot level, actors operating within those organisations such as such digital champions, tutors, and trainers that enables the realisation of the provision of digital inclusion initiatives.

Stakeholders revealed that several rules influence this activity (explicitly or implicitly), specifically digital policy and digital skills training frameworks; funding and political environment; knowledge sharing, and the differing cultural and operation practices between organisations. It is the influence of policy on the shared object that is the focus of this paper and its interrelations with the other elements of the activity. For example, from the document analysis and stakeholder interviews, it can be ascertained that digital inclusion in the UK is approached and driven through national digital inclusion policies and strategies. As a devolved issue, each nation within the UK has its own policy. For example, England has the UK 
government digital inclusion strategy (2014); Scotland has the Realising Scotland's full potential in a digital world: a digital strategy for Scotland (2017); and Wales has the Delivering Digital Inclusion Strategy $(2007,2010)$. Each digital inclusion policy hass a slightly different stance. The policy for England has a focus on skills and capabilities; the Welsh digital inclusion strategy focuses on social justice and social inclusion; whereas the Scottish strategy focuses on improving digital participation across communities and digital future proofing. When describing their retrospective policies, stakeholders drew parallels with the shared goal of achieving digitally included citizens, while also highlighting misalignment between the UK nations digital inclusion strategies and the UK's overarching government digital inclusion strategy (Cabinet Office, 2014). This strategy was published as part of the UK government digital strategy (Cabinet Office, 2013) which amongst other things set out how government services were to change to 'Digital-by-Default'. As stated:

"Moving to Digital-by Default means that, over time, government will provide digital services so straightforward and convenient that all those who can use them will choose to do so, whilst those who can't are not excluded" (Cabinet Office, 2013).

The digital strategy (Cabinet Office 2013; DCMS, 2017) goes on to state that those not online will be supported through 'Assisted Digital' as explained:

"To ensure that people who are offline can access Digital-by-Default services, we will offer them ways to access services offline, and we will provide additional ways for them to use the digital services. These services must be designed to meet user needs. We call this 'assisted digital'," (Cabinet Office, 2013).

However, findings from stakeholders reveal how these policies have brought challenges to the digital inclusion arena and the provision of digital inclusion initiatives. These are explained next.

An important finding is the need for a shared understanding among the stakeholders of the role of intermediaries in digital inclusion initiatives provision:

"Libraries are definitely a key actor, in terms of digital inclusion especially in rural communities" [Project manager within government funded organisation] 
Stakeholders further evidenced their shared understanding of the UK digital inclusion agenda through citing policy documents such as the UK Government Digital Inclusion Strategy (Government Digital Service, 2014); individual digital inclusion strategies for Scotland and Wales; the Essential Digital Skills Framework; and the recently introduced Basic Digital Skills Entitlement. Indeed, stakeholders referred to digital inclusion policy in a positive light, rather than providing a more critical perspective on digital inclusion policy.

However, the findings also reveal how stakeholders recognise that achieving a shared understanding in digital inclusion initiative provision is challenging, due to the multiple factors which contribute to digital exclusion.

"The problem with people being offline there is not a one size fits all. People have often got other issues happening in their lives. They may have complex needs. There are reasons why they are not online. Most people who don't have those complex needs and barriers are online" [Programme manager at third sector organisation]

Furthermore, whilst stakeholders provided some evidence of sharing best practice and innovative ideas, through the use of policy level events and steering groups, they also revealed that there is a need for greater alignment and knowledge sharing.

"The more we can create forums to exchange knowledge and discuss the better. I don't think there has been enough of those spaces" [UK Government official within digital]

Stakeholders also evidenced a shared understanding of how they are dependent on delivering digital inclusion initiatives through intermediary organisations who are in the unique position of being able to reach and collaborate with communities at grassroot level.

"We work through intermediary organisations. We want to make sure that we are working closely with a whole host of organisations who have those relationships with individuals. Its trusted people in local places who are going to help those who are not online" [Head of service of government funded organisation]

Indeed, the findings highlight the important role of intermediary organisations, digital champions, the local assets in which digital inclusion practice takes place, but also the various tools used to engage and deliver digital skills training and support. Furthermore, how digital inclusion initiatives target specific subgroups by engaging through existing social, cultural or 
support groups, and/or through using local trusted community assets such as local schools, libraries, churches, community centres.

"In order to help these people to get online, the most likely person to help them is someone who is trusted, someone who has understanding of why they need to be online, can help them with skills, motivation and confidence" [Head of service of government funded organisation]

Stakeholders revealed how digital champions deliver a high percentage of face-to-face digital skills training through intermediaries, and are either volunteers (often students, the unemployed and the retired), or professionals (such as paid, qualified tutors and inhouse staff).

"We have champions that volunteer at job centres and job clubs, but we also have people who are just available in their community, and community areas" [Programme manager at third sector organisation]

Stakeholders also revealed how digital champions within organisations where they can train staff within their own place of work and engage with the public through their frontline role, or through a community building role where the digital champions "use their digital champion skills to help solve their problems" [Programme Director of third sector organisation]

Digital skills training is provided through the use of PCs, laptops, mobile phones and tablets, VR headsets, either through tailored resources or specific online digital skills content, often on a theme or information need, such as health information, relevant to individuals' context.

Some stakeholders revealed they provide digital training to front-line workers who are perhaps more engaged with digitally excluded communities as part of their everyday work.

Interestingly while digital skills training was discussed, very little information was shared in relation to stakeholders' perspectives on how individuals learn digital skills or any relevant learning theories, indicating a gap in the understanding of individuals' needs.

\section{Contradictions}

As mentioned earlier, a fundamental concept in AT is the notion of identifying contradictions within an activity system, which expose the dynamics, inefficiencies and opportunities for change within an activity system. 
Contradictions have been identified which link to the contrasting organisational cultures, operational practices and social agendas of the different subjects of the activity system, which in itself manifests a contradiction. Contradictions emerged within the subject element when considering the perspectives or silences from government officials.

A dominant contradiction is that despite the strategic intent of government policy to determine and influence the provision of digital inclusion initiatives through partnership working and collaboration, there are increasing tensions in relation to the government's Digital-by-Default agenda. Specific tensions relate to the movement of commercial and government services going online, and the impact this has on digitally excluded communities.

"We can see the UK Government have made big changes to their digital platform, but the danger is so much has been removed from the analogue channel that people who are [digitally] excluded get a really poor service now" [Project manager within government funded organisation]

Third sector and digital leader stakeholders argued specifically how Universal Credit (part of the UK government's Digital-by-Default agenda) is having a disruptive effect on digital inclusion initiative provision and the day-to-day operations of intermediary organisations as explained by one stakeholder:

"Before [universal Credit] people were turning up to centres for the social contact, progression to further learning, the whole digital inclusion journey. Now demand has overtaken by people coming through the door saying 'I just need to be on Universal Credit so I can feed my family so I know I have money at the end of the week and I don't know how to do it',' [Head of research of third sector organisation]

This reveals a significant contradiction within the rules element of the activity system between the UK Digital Strategy (Cabinet Office 2013; DCMS, 2017) and national digital inclusion policies, which may hinder the realisation of the object of the activity system.

Another significant contradiction was in relation to the reliance on intermediaries delivering digital skills training and support as encouraged through digital inclusion policies. Digital inclusion policy not only assumes intermediaries have the necessary skills and resource to do this, but also that they are willing to collaborate as part of this process. However, findings of 
this study indicate significant contradictions in relation to the application of digital inclusion policy and the reliance on intermediary organisations as outlined below:

Government official stakeholders indicated that they assume intermediaries have sufficient digital and teaching skills themselves to support digitally excluded communities:

"It's something that we trust providers [intermediaries] to make decisions on as professionals" [Team leader in UK Government Department]

However, as pointed out by third sector and digital leader stakeholders, if the necessary skills are not in place for such intermediaries, this hinders the effectiveness of digital inclusion initiatives.

"we need to get a general level of professionalism in roles which are directly interfacing with people who are digitally excluded. They need to feel confident and enabled to pass on the right type of skills and knowledge. They have the relationship in place, but they are missing the other side [digital skills]" [Director of a trust organisation]

Third sector and digital leader stakeholders also highlighted increased tensions amongst intermediary organisations in relation to being relied upon to provide digital inclusion support whilst struggling with funding particularly in rural locations:

"Government is very much reliant on the good will of organisations to do [digital inclusion work] that they are not so keen to spend money on. Digital inclusion is not suitably funded and there is a lack of commitment from government" [Programme manager at third sector organisation]

This highlights a contradiction between the tools, division of labour and community elements of the activity system. Indeed, funding cuts were mentioned by third sector and digital leader stakeholders as barriers/hinderers to implementing and delivering digital inclusion initiatives, particularly in rural areas highlighting contradictions between the rules, community and division of labour elements which ultimately impact the outcome of the activity system.

"Not so many organisations are doing digital inclusion outreach work in rural areas largely due to the costs of travelling and the lack of funding. It's difficult to get funding for rural areas" [Director of a third sector organisation] 
This indicates that despite limited funding and resource intermediary organisations are willing to help individuals in need of digital inclusion support, but highlights frustrations with policymakers and government funding in pursuing this objective.

The assumption from government officials that intermediaries have sufficient digital skills and resource to provide digital inclusion training demonstrates a significant contradiction within the subject element of the activity system but also between the community, division of labour and tools elements of the activity system in relation to achieving the shared object.

Another aspect of digital inclusion policy is the need to provide evaluations on digital inclusion initiatives. Whilst discussing their involvement in evaluations, stakeholders revealed a lack of trust between funders and those evaluating digital inclusion initiatives. For example, the stakeholders described how evaluations require to include a number of aspects such as performance, number of people reached, and what has worked well, as revealed by one government official, there is a tendency to present these evaluations as quite positive.

Another significant contradiction revealed is in relation to how the distribution of technological and local infrastructure affects the application of digital inclusion policy. Third sector and digital leader stakeholders questioned the Government commitment that universal high-speed broadband and particularly to rural areas and the difficulties with geography and infrastructure. As explained:

"Infrastructure is difficult in rural areas. It's more sustainable to have broadband where there is commercial pressure or investment in broadband" [Head of service of government funded organisation]

While acknowledging the improvement of digital connectivity, stakeholders referred to how the poor quality of connectivity and closure of local assets, where there are no other alternative venues for digital inclusion engagement and facilities, exemplified digital exclusion, particularly in rural communities.

"How we tackle it [digital exclusion] in rural communities is a big issue and one that we are probably only just beginning to get to grips with" [Project manager within government funded organisation] 
These findings therefore highlight a contradiction between the tools and object elements of this activity system as inequality in terms of technological and local infrastructure in rural communities hampers digital inclusion support and provision, as summed up by these stakeholders:

"We have hugely been aware for a long time of the inequalities gap in terms of [digital inclusion] provision particularly in rural areas. Obviously, you have the sparsity of the population but that doesn't actually equal sparsity of need" [Head of research of third sector organisation]

"Local community organisations have an understanding of what local assets are available, and can use those assets to build relationships such as using WIFI from another organisation. However, in a rural area they [local community organisations] have fewer choices about those things [assets] because internet connection is more of an issue and assets are depleting in rural areas" [Evaluation manager]

To sum up, through the use of AT, the findings provide a policy-level perspective on how digital inclusion initiative provision is tackled in UK rural communities and how the process is fraught with difficulties and contradictions, which hampers the realisation of the object of the activity system in achieving the beneficial outcomes of digital inclusion. The next section provides a discussion.

\section{Discussion}

This study provides a policy-level perspective from digital inclusion stakeholders operating nationally, whose roles enable them to be able to provide insight of how policy tackles digital inclusion through the provision of digital inclusion initiatives in the context of UK rural communities, and across the UK. Findings and contradictions were identified through the utilisation of AT and are discussed next.

The findings reveal that stakeholders emphasise the benefits of digital inclusion with references to social inclusion, reflecting the positive rhetoric in digital inclusion policy documents and stakeholder agenda. Indeed, such positive perspective is highlighted by scholars (Eubanks, 2011; Mori, 2011; Gangadharan, 2017). However, as evidenced in the literature, not everyone who is socially excluded is digitally excluded and vice versa (Meryvn et al., 2014; Taylor and Packham, 2016; Buré, 2006). However, is digital inclusion the panacea to digital inequalities? 
Indeed, this "utopian" discourse in digital inclusion agenda has been identified by scholars (Gangadharan, 2017; Mori, 2011) and as such supports the need to gain a more critical perspective on digital inclusion. Jaeger et al. (2012) explain "it is a challenge to solve a problem you cannot define, and the inconsistency of definitions has affected policy-making processes that have attempted to address these issues" (p.4). As highlighted by this study and through the use of AT achieving the object of creating/translating policy and the provision of digital inclusion initiatives is not straightforward and is entangled with difficulties and contradictions, which not only hamper the realisation of the object of the activity system, but also in achieving the outcomes. The use of AT has enabled a critical analysis of a policy-level perspective on digital inclusion and digital inclusion initiative provision.

For example, the findings have demonstrated the lack of an unified way of realising digital inclusion initiative provision. Through the use of AT, it emerged that different organisations translate the digital policy in a number of ways as these assume variety of roles, within organisations with contrasting organisational cultures and operational practices. This in turn has led to contradictions, which could dismantle the activity system. While the lack of unison could be construed as a weakness within the digital inclusion realm, it could also be argued that the multi-stakeholder involvement at policy-level has the potential to be a strength and opportunity for change due to the multiple stakeholder perspectives at policy-level. However due to the lack of knowledge sharing opportunities across the stakeholder organisations and an indication of a lack of trust between some of the stakeholders, most notably with government departments, the successful provision of digital inclusion initiatives appears weak. Indeed, very little reference is made to knowledge sharing in digital inclusion literature and warrants further research. Exceptions include Roberts et al. (2017a) in which their review on rural digital policy agenda, highlighted the importance of knowledge sharing within the DAE, the Gdansk Roadmap for Digital Inclusion initiative developed in 2011. The scholars identified how knowledge sharing and development of common tools to make the task of digital inclusion training by volunteers and third sector via partnerships easier. However, the importance of knowledge sharing in digital inclusion policy and academic literature appears scarce.

The findings also demonstrate a more critical stance on how policy influences digital inclusion initiative provision, most notably on issues related to the devolution of authority and service provision from centralised, government departments to local public and private sector agencies (Letch and Carroll, 2008; Philip et al., 2017); and the UK's Digital-by-Default agenda and 
austerity (Hepburn, 2018; Mervyn et al., 2014). Indeed, research by Yates et al. (2015) identified that the Digital-by-Default approach to online services has underestimated issues of usability across a varied population, resulting in benefit claimants unable to use such systems, having to rely on support from intermediary organisations to navigate online services, thus adding demand to the existing digital inclusion work of support organisations. Indeed, as revealed in the findings, through contradictions in the activity system, the underpinning assumption that digital inclusion stakeholders will collaborate in partnership to deliver digital inclusion initiatives (as indicated in the UK digital strategy (Cabinet Office 2013; DCMS, 2017)), is flawed and highlights a significant misalignment between the expectations of policymakers and the ability and good will of intermediary organisations which provide digital inclusion training and support with lack of resources, trust and knowledge sharing. The reliance on intermediaries to reach out, engage and support digitally excluded individuals (Torrecillas et al., 2014), was emphasised in the findings. However, as highlighted in the findings there is a need for such intermediaries to have the right skills to be able to impart this knowledge onto others. Indeed, as stated by Yates et al. (2015) there is an argument for increasing support for third-sector organisations, who provide digital skills training and digital access, due to increased demand being placed on their digital inclusion services by individuals and communities who need support to cope with processes implemented through channel shift and Digital-by-Default. However, as indicated in the findings, not all intermediaries have the necessary skills and unless they receive training, will fail to provide adequate support.

In relation to the rural context, such contradictions were even more prominent. The findings revealed that digital inclusion initiatives discussed tended to have a targeted community-based approach to specific groups of society, but none were specifically focussed on rural areas (Gangadharan, 2017; Mariën and Van Audenhove, 2012; Taylor and Packham, 2016). Indeed, scholars highlight how the UK digital strategy includes no specific rural digital inclusion initiatives for reducing barriers of skills, motivation or trust, but focuses instead on access (Philip and Williams, 2019). This discourse in policy research on the provision of digital inclusion initiatives in UK rural communities tends to be dominated by broadband initiatives (Roberts et al., 2017a; Philip and Williams, 2019). An important finding and contradiction in this study is how the provision of digital inclusion initiatives in rural areas is hampered by the lack of local resources, reduced or poor-quality connectivity and lack of funding. Indeed, as identified by scholars the process of applying for funding is complicated (Mariën and Prodnik, 2014) and particularly difficult for smaller organisations who do not necessarily have the 
resources, such as those operating in rural areas (Real et al., 2014). This therefore raises the question if rural communities would be better supported through more tailored approaches to digital inclusion initiative provision such as asset-based community development approaches (Reisdorf and Rhinesmith, 2018) which consider the context of the rural communities and their needs. However, findings from this study are from a policy-level perspective.

For example, Park et al. (2019) suggest a customised policy framework is required which to consider the diversity and uniqueness of local contexts in connectivity and digital inclusion. For example, Helsper and Van Deursen (2017) identified that the quality of support people have access to is unequally distributed and replicates existing inequalities. In other words, it is not only a matter of skills but also the context and communities that influence digital inclusion. Therefore, the rural context of this study as highlighted in the findings, influences the digital inclusion potential of these communities and needs to be considered alongside their digital skill abilities. Indeed, Borg et al. (2018) refers to the importance of social support as one of the key enablers of digital inclusion.

\section{Conclusions}

This paper provides new insights into the understanding of how policy-level stakeholders tackle digital inclusion and the provision of digital inclusion initiatives and provides recommendations to resolve the challenges. It builds on the use of AT to help unravel the complexity of digital inclusion as a phenomenon and demonstrates how AT can provide a robust and holistic framework to study and gain a better understanding of digital inclusion, and explore the challenges of implementing and delivering digital inclusion initiative provision within UK rural communities. The use of AT has also helped to highlight the perspectives and differing views of policy-level digital inclusion stakeholders, and signpost ways to improve digital inclusion initiative practice in the future. The research outlines the following contributions:

The first contribution is that AT enables to research and understand the actors, structure and the selection of tools and their development, within a coherent framework of the activity system. Hence the research was able to capture the cultural-historical context, the role of ICT in human activity and a more critical perspective of digital inclusion initiatives that highlights criticisms aimed at digital policy specifically the UK government's Digital-by-Default agenda, 
distribution of technological and local infrastructure and funding, and the reliance on intermediaries.

The second contribution is the of the identification and understanding of contradictions at the digital inclusion policy-level. The findings reveal contradictions in the areas of trust, and the need for knowledge sharing mechanisms to span and align different interpretations of digital inclusion stakeholders.

The third contribution importantly signifies an extension of AT, which is to demonstrate the multi-actor involvement of the stakeholders involved in digital inclusion at policy-level through the subject element. Learnings from this study indicate when utilising AT, scholars need to consider the subjects of the activity system, which to a certain extent could emerge as unknown or could change. This is particularly applicable for situations such as digital inclusion which is complex and experiencing rapid change. For example, to understand digital inclusion from a policy-level perspective, scholars may approach this by recruiting policymakers as subjects of the AT. However, this provides a rather narrow perspective of policy. A richer data set will be appropriated by considering other actors who span other levels, for example, subjects who are at policy-level and at intermediary level. Inclusion of such subjects generate more critical insights from multiple perspectives, that reveal any hidden silences, contradictions and opportunity for change.

Finally, the fourth contribution of this paper is that it provides a policy-level perspective on how digital inclusion stakeholders operating nationally tackle digital inclusion and the provision of digital inclusion initiatives in the context of UK rural communities. This paper is unique in that it has provided insights from stakeholders who contribute to policy development and committees; translate digital policy, and national digital inclusion policies and strategies in practice; and create digital policy, capturing a critical discussion from a policy-level perspective.

This paper has a number of implications for policy and future research. The findings and contradictions in this paper indicate the need for consideration in policy for the provision of digital inclusion initiatives not to reinforce the exclusion of any already marginalised communities. Considerations need to be given to rural populations who struggle with challenges such as reliable Internet connectivity, and reduced local resource. Reliance on intermediary organisations to support people with their digital capabilities also need to be 
considered to ensure such intermediaries have the necessary funding and digital skill set to be able to support others. Also, with the evolving nature of the digital inclusion arena, it is recommended that increased knowledge sharing among the UK nations is sought through a shared space/forum to discuss how policy-level stakeholders tackle digital inclusion initiative provision particularly in rural areas to improve their shared understanding of the application of digital inclusion policy. It would also provide stakeholders with crucial knowledge for funding applications and evaluations. However, it is the misalignment between the UK digital inclusion strategy (2014) and the current UK digital strategy (Cabinet Office 2013; DCMS, 2017) that warrants most concern. In its current state it could be argued that the Digital-by-Default implemented through the digital strategy has further driven the need for digital inclusion initiatives that provide digital training and support. However, what is evident is that while Digital-by-Default continues to be rolled out there are proportions of society who cannot access online services particularly in rural contexts. This is particularly crucial with the issues raised in relation to processes implemented through Digital-by-Default, Universal Credit and funding cuts, the current global pandemic and restrictions which require access and capable use of digital technologies. The paper argues that future policy needs to consider how structures and system mechanisms, such as Digital-by-Default online services, disintermediation of service provision, the distribution of technological and local infrastructure, and funding distribution, impacts rural communities but also those intermediary organisations in which government is reliant on in delivering digital inclusion initiatives.

We note several limitations in our study, which also act as extensions for future research. First the study focuses on the policy-level perspective on digital inclusion and the provision of digital inclusion initiatives. In order to gain a richer understanding of how the provision of digital inclusion should be approached in rural communities, a more granular study is required that takes into account stakeholders that operate across multiple levels, from national and intermediary-level organsations, through to grassroot organisations and recipients of digital inclusion training support. Another limitation to this paper is while reference to digital inclusion initiatives is made, a thorough investigation of such initiatives in relation to approaches taken warrants further research. Furthermore, this study is set in the context of the UK (excluding Northern Ireland) with a focus on rural communities. The research could also get extended to include Northern Ireland or other global contexts provides a fruitful avenue for future research. 
This study argues that future research needs to gain a more critical perspective of digital inclusion initiatives and to incorporate insights from digital inclusion initiative stakeholders operating at policy, national, intermediary and individual-level.

\section{References}

Aires, L. (2014), "From dissemination to the domestication of digital technologies in rural communities: Narratives of parents and teachers", Mind, Culture, and Activity, Vol. 21 No. 4, pp. 337-352.

Al-Muwil, A., Weerakkody, V., El-haddadeh, R. and Dwivdei, Y. (2019), "Balancing DigitalBy-Default with Inclusion: A Study of the Factors Influencing E-Inclusion in the UK", Information Systems Frontiers, Vol. 21 No. 3, pp. 635-659.

Asmar, A., van Audenhove, L and Mariën, I. (2020), "Social Support for Digital Inclusion: Towards a Typology of Social Support Patterns”, Social Inclusion, Vol. 8 No. 2, pp. 138-150. Ashmore, H., Farrington, J.H. and Skerratt, S. (2015), "Superfast Broadband and Rural Community Resilience: Examining the Rural Need for Speed", Scottish Geographical Journal, Vol. 131 No. 3-4, pp. 265-278.

Aziz, A. (2020). Digital inclusion challenges in Bangladesh: the case of the National ICT Policy, Contemporary South Asia, Vol 28, No. 3, pp. 1-16.

Bach, A., Shaffer, G. and Wolfson, T. (2013), "Digital human capital: Developing a framework for understanding the economic impact of digital exclusion in low-income communities", Journal of Information Policy, Vol. 3, pp. 247-266.

Beattie-Smith, S. (2013), Offline and left behind: Digital exclusion amongst Scotland's CAB clients, Citizens Advice Scotland, Edinburgh, available at: http://bit.ly/2oIKtF9 (accessed 15 January 2020).

Borg, K., Boulet, M., Smith, L. and Bragge, P. (2018), "Digital Inclusion \& Health Communication: A Rapid Review of Literature", Health Communication, pp. 1-9.

Bradbrook, G. and Fisher, J. (2004), Digital Equality: Reviewing digital inclusion activity and mapping the way forwards. London: CitizensOnline, available at: http://www.citizensonline.org.uk/site/media/documents/939 DigitalEquality1.pdf (accessed 15 January 2020).

Braun, V. and Clarke, V. (2006), "Using thematic analysis in psychology", Qualitative research in psychology, Vol. 3 No. 2, pp. 77-101. 
Bryman, A. (2012), Social research methods. Oxford: Oxford University Press.

Buchanan, S., Jardine, C. and Ruthven, I. (2018), "Information behaviors in disadvantaged and dependent circumstances and the role of information intermediaries", Journal of the association for information science and technology, Vol. 70 No. 2, pp. 117-129.

Buré, C. (2006), "Digital Inclusion without Social Inclusion: The Consumption of Information and Communication Technologies (ICTs) in Homeless Subculture in Central Scotland", The Journal of Community Informatics, Vol. 2 No. 2, pp. 116-133.

Bryman, A. (2012), Social research methods. Oxford: Oxford University Press.

Cabinet Office (2013). Government Digital Strategy. Available at

https://www.gov.uk/government/publications/government-digital-strategy/government-

digital-strategy (accessed 15 January 2020).

Cabinet Office (2014). Government Digital Inclusion Strategy. Available at

https://www.gov.uk/government/publications/government-digital-inclusion-

strategy/government-digital-inclusion-strategy (accessed 15 January 2020).

Clayton, J. and MacDonald, S. (2013), “The limits of technology: social class, occupation and digital inclusion in the city of Sunderland, England", Information Communication and Society, Vol. 16, No. 6, pp. 945-966.

Correa, T. and Pavez, I. (2016), "Digital inclusion in rural areas: A qualitative exploration of challenges faced by people from isolated communities", Journal of Computer-Mediated Communication, Vol. 21 No. 3, pp. 247-263.

Courtois, C. and Verdegem, P. (2016), "With a little help from my friends: An analysis of the role of social support in digital inequalities" New Media \& Society, Vol. 18 No.8, pp. 15081527.

Cowie, P., Townsend, L. and Salemink, K. (2020), "Smart rural futures: Will rural areas be left behind in the 4th industrial revolution?” Journal of Rural Studies, Vol. 79, pp. 169-176.

Cushman, M. and McLean, R. (2008), "Exclusion, inclusion and changing the face of information systems research", Information Technology \& People, Vol. 21 No.3, pp. 213-221. Creswell, J.W. (2009), Research design: qualitative, quantitative, and mixed methods approaches. 3rd ed. Thousand Oaks, CA.; London: Sage Publications.

Davies, H.C., Eynon, R. and Wilkin, S. (2017), "Neoliberal gremlins? How a scheme to help disadvantaged young people thrive online fell short of its ambitions", Information, Communication \& Society, Vol. 20 No. 6, pp. 860-875.

DCMS (2014), Government Digital Inclusion Strategy. Department of Digital Culture Media \& Sport. Available at https://www.gov.uk/government/publications/uk-digital-strategy/2- 
digital-skills-and-inclusion-giving-everyone-access-to-the-digital-skills-they-need (accessed 15 January 2020).

Díaz Andrade, A. and Doolin, B. (2019), “Temporal enactment of resettled refugees' ICT-mediated information practices”, Information Systems Journal, Vol. 29 No. 1, pp. 145174.

Díaz Andrade, A. and Techatassanasoontorn, A.A. (2021), "Digital enforcement: Rethinking the pursuit of a digitally-enabled society", Information Systems Journal, Vol. 31, No.1, pp. 184-197.

Eisenhardt, K.M. (1989), "Building theories from case study research", The Academy of Management Review Vol.14 No.4, pp. 532-550.

El-Haddadeh, R., Weerakkody, V., Osmani, M., Thakker, D. and Kapoor, K. (2019), “Examining citizens' perceived value of Internet of things Technologies in Facilitating Public Sector Services Engagement", Government Information Quarterly, Vol. 36 No. 2, pp. 310320.

Engeström, Y. (1993), Developmental studies of work as a testbench of activity theory: The case of primary care medical practice. In S. Chaiklin \& J. Lave (Eds.), Understanding practice: Perspectives on activity and context (pp. 64-103). New York, NY: Cambridge University Press. Engeström, Y. (1987), Learning by expanding: An activity-theoretical approach to developmental research, Orienta-Konsultit: Helsinki.

Engeström, Y. (1999), "Innovative learning in work teams: analysing cycles of knowledge creation in practice", in: Engeström, Y. et al (Eds.) Perspectives on Activity Theory. Cambridge University Press.

Engeström, Y. (2001), Expansive learning at work: Toward an activity theoretical reconceptualization. Journal of Education and Work, Vol. 14 No.1, pp. 133-156.

Engeström, Y. and Sannino, A. (2010), "Studies of expansive learning: Foundation, findings and future challenges", Educational Research Review, Vol. 5 No. 1, pp. 1-24.

Eubanks, V. (2011), Digital Dead End: Fighting for Social Justice in the Information Age. Cambridge, MA: MIT Press.

Fang, M., Canham, L., Battersby, L., Sixsmith, J., Wada, M. and Sixsmith, A. (2019), "Exploring privilege in the Digital Divide: Implications for Theory, Policy and Practice", The Gerontologist, Vol. 59 No. 1, pp. 1-15.

Faulkner, W. and Kleif, T. (2005), One size does not fit all! Gender in/exclusion in a rural community-based ICT initiative, Journal of Adult and Continuing Education, Vol. 11 No.1, pp. 43-61. 
Gangadharan, S. (2017), “The downside of digital inclusion: Expectations and experiences of privacy and surveillance among marginal Internet users”, New Media and Society, Vol. 19 No.4, pp. 597-615.

Gann, B. (2019), "Digital Inclusion and Health in Wales", Journal of Consumer Health on the Internet, Vol. 23 No. 2, pp. 146-160.

Gerli, P. and Whalley, J. (2018), "Fiber to the Countryside: A Comparison of Public and Community Initiatives in the UK", TPRC 46: The 46th Research Conference on

Communication, Information and Internet Policy. Available at http://dx.doi.org/10.2139/ssrn.3137164.

Gerli, P., Matteucci, N. and Whalley, J. (2020), "Infrastructure Provision on the Margins: An Assessment of Broadband Delivery UK", International Journal of Public Administration, Vol. 43 No. 6, pp. 540-551.

Gomez, R. and Gould, E. (2010), “The “cool factor” of public access to ICT: Users' perceptions of trust in libraries, telecentres and cybercafés in developing countries", Information Technology and People, Vol. 23 No. 3, pp. 247-264.

Gordo, B. (2015), "Roads and Roadblocks to Digital Inclusion: An Analysis of a Public Policy Program in California", Communication and Information Technologies Annual: Digital Distinctions and Inequalities Studies in Media and Communications, Vol.10, pp. 235-288.

Gorman, G.E. and Clayton, P. (2005), Qualitative Research for the Information. Professional: A Practical Handbook. 2nd ed London: Facet Publishing.

Gripenberg, P. (2011), "Computer self-efficacy in the information society", Information Technology \& People, Vol. 24 No.3, pp. 303-331.

Hache, A. and Cullen, J. (2009), ICT and Youth at Risk: How ICT-driven initiatives can contribute to their socio-economic inclusion and how to measure it. European Commission, JRC Scientific and Technical Reports, RC58427.

Hamburg, I. and Lütgen, G. (2019), "Digital Divide, Digital Inclusion and Inclusive Education", Advances in Social Sciences Research Journal, Vol. 6 No. 4, pp. 193-206.

Hashim, N. and Jones, M.L (2007), Activity theory: a framework for qualitative analysis, International Qualitative Research Convention.

Helsper, E (2008), Digital Inclusion: An analysis of social disadvantage and the information society. Department for Communities and Local Government, London, UK.

Helsper, E. (2012), “A corresponding fields model for the links between social and digital exclusion", Communication Theory, Vol. 22 No. 4, pp. 403-426. 
Helsper, E. and Reidorf, C. (2017), “The emergence of a 'digital underclass' in Great Britain and Sweden: changing reasons for digital exclusion", New Media \& Society, Vol. 19 No. 8, pp. 1253-1270.

Helsper, E. (2017), "The social relativity of digital exclusion: applying relative deprivation theory to digital inequalities", Communication Theory, Vol. 27 No. 3, pp. 223-242.

Helsper, E.J. and Van Deursen, A. (2017), "Do the rich get digitally richer? Quantity and quality of support for digital engagement”, Information, Communication \& Society, Vol. 20 No. 5, pp. 700-714.

Hepburn, P. (2018), “A New Governance Model for Delivering Digital Policy Agendas: A Case Study of Digital Inclusion Amongst Elderly People in the UK”, International Journal of E-Planning Research, Vol. 7 No. 3, pp. 36-49.

House of Commons (2019) An Update on Rural Connectivity: Seventeenth Report of Session 2017-2019, House of Commons Environment, Food and Rural Affairs Committee.

Helle, M. (2000), "Disturbances and contradictions as tools for understanding work in the newsroom”, Scandinavian Journal of Information Systems, Vol. 12, pp. 81-113.

Huggins, R. and Izushi, H. (2002), "The Digital Divide and ICT Learning in Rural Communities: Examples of Good Practice Service Delivery", Local Economy, Vol.17 No.2, pp. 111-122.

Iordache, C., Mariën, I. and Baelden, C. (2017), "Developing Digital Skills and Competences: A Quick- Scan Analysis of 13 Digital Literacy Models”, Italian Journal of Sociology of Education, Vol. 9 No. 1, pp. 6-30.

Jaeger, P.T., Bertot, J.C., Thompson, K.M., Katz, S.M., and DeCoster, E.J. (2012), "The intersection of public policy and public access: Digital divides, digital literacy, digital inclusion, and public libraries", Public Library Quarterly, Vol. 31 No.1, pp. 1-20.

Jussila, J., Sillanpää, V., Lehtonen, T., Helander, N., and Frank, L. (2019), An Activity Theory Perspective on Creating a New Digital Government Service in Finland. In Proceedings of the 52nd Hawaii International Conference on System Sciences.

Karanasios, S. and Allen, D.K. (2013), "ICT for development in the context of the closure of Chernobyl nuclear power plant: an activity theory perspective", Information Systems Journal, Vol. 23 No. 4, pp. 287-306.

Karanasios, S. (2018), "Toward a unified view of technology and activity: The contribution of activity theory to information systems research", Information Technology and People, Vol. 31 No.1, pp. 134-155. 
Klecun, E. (2008), "Bringing lost sheep into the fold: Questioning the discourse of the digital divide”, Information Technology \& People, Vol. 21 No. 3, pp. 267-282.

Kuutti, K. (1996), “Activity Theory as a Potential Framework for Human-Computer Interaction Research", in Nardi (Ed.). Context and Consciousness: Activity Theory and Human Computer Interaction Cambridge: MIT Press.

Leontev, A.N. (1978), Activity, Consciousness, and Personality, Prentice-Hall, Englewood Cliffs, NJ.

Letch, N. and Carroll, J. (2008), "Excluded again: implications of integrated e-government systems for those at the margins", Information Technology \& People, Vol. 21 No. 3, pp. 283299.

Lincoln, Y.S. and Guba, G. (1985), Naturalistic inquiry. Thousand Oaks, C.A: Sage.

López, J., Castañeda, L.A. and Reyes, J.P. (2018), "Models with a social perspective for the management of digital inclusion processes", International Journal of Latest Research in Humanities and Social Science, Vol. 1 No. 3, pp. 73-83.

Macpherson, A. (2006), Learning to grow: the evolution of business knowledge in small manufacturing firms. $\mathrm{PhD}$, Manchester Metropolitan University.

Madon, S., Reinhard, N., Roode, D. and Walsham, G. (2009), "Digital inclusion projects in developing countries: Processes of institutionalization", Information Technology for Development, Vol. 15 No.2, pp. 95-107.

Mahmood, M., Weerakkody, V. and Chen, W. (2018), "The influence of transformed government on citizen trust: Insights from Bahrain", Information Technology for Development, Vol. 25 No. 2, pp. 275-303.

Mariën, I. and Van Audenhove, L. (2011), Mediageletterdheid en digitale vaardigheden: naar een multidimensioneel model van digitale exclusie. In Mediageletterdheid in een digitale wereld, Studiedienst Vlaamse Regering.

Mariën, I. and Van Audenhove, L. (2012), “Towards a multi-stakeholders approach for digital inclusion: A case study of Ghent's 'Digital.Talent' policy program”, IAMCR2012 Conference, South Africa.

Mariën, I. and Prodnik, J. (2014), "Digital inclusion and user (dis) empowerment: a critical perspective", Info Vol. 16 No. 6, pp. 35-47.

Mariën, I. (2016), The dichotomy of the digital divide breaks through: A study of the causes of digital exclusion and strategies for a sustainable e-inclusion policy. Unpublished dissertation Vrije Universiteit.

Mason, J. (2002), Qualitative researching (2nd ed.). Thousand Oaks, CA: Sage Publications. 
Mervyn, K., Simon, A. and Allen, D.K. (2014), "Digital inclusion and social inclusion: a tale of two cities", Information, Communication \& Society, Vol. 17 No. 9, pp. 1086-1104.

Miles, M., Huberman, A.M. and Saldaña, J. (2014), Qualitative data analysis: A methods sourcebook. Thousand Oaks, California: SAGE Publications.

Mori, C.K. (2011), “'Digital Inclusion': Are We All Talking about the Same Thing?” In Steyn, J. and Johanson, G. (Eds.), ICTs and Sustainable Solutions for the Digital Divide: Theory and Perspectives (pp. 45-64). Hershey, PA: IGI Global.

Myers, M. and Newman, M. (2007). The qualitative interview in IS research: Examining the craft. Information and Organization, Vol. 17 No 1, pp. 2-26.

Nemer, D. (2015), From digital divide to digital inclusion and beyond: A positional review. Journal of Community Informatics, Vol. 11 No.1, pp. 1-9.

Park, S., Freeman, J. and Middleton, C. (2019), "Intersections between connectivity and digital inclusion in rural communities", Communication Research and Practice, Vol. 5 No. 2, pp. 139155.

Philip, L., Cottrill, C., Farrington, J., Williams, F. and Ashmore, H. (2017), “The digital divide: patterns, policy and scenarios for connecting the 'final few' in rural communities across Great Britain”, Journal of Rural Studies, Vol. 54, pp. 386-398.

Philip, L. and Williams, F. (2019), "Remote rural home-based businesses and digital inequalities: Understanding needs and expectations in a digitally underserved community", Journal of Rural Studies, Vol, 68, pp. 306-318.

Philip, L. and Williams, F. (2019a), Healthy ageing in smart villages? Observations from the field, European Countryside, Vol. 11 No. 4, pp. 616-633.

Polat, R.K. (2012). Digital exclusion in Turkey: A policy perspective, Government Information Quarterly, Vol. 29, No.4, pp. 589-596.

Prenkert, F. (2006), "A theory of organizing informed by activity theory: the locus of paradox, sources of change, and challenge to management", Journal of Organizational Change Management, Vol.19 No. 4, pp. 471-490.

Ragnedda, M. (2018), "Reducing and preventing digital discrimination - Digital inclusion strategies in Europe", in Ragnedda, M. and Mutsvairo, B. (Eds.), Digital Inclusion: an international comparative analysis. Lanham, MD: Rowman \& Littlefield.

Real, B., Bertot, C. and Jaeger, P.T. (2014), "Rural public libraries and digital inclusion: Issues and challenges", Information Technology and Libraries, Vol. 33 No. 1, pp. 6-24.

Reisdorf, C. and Rhinesmith, C. (2018), "Digital Inclusion in International Perspective-An Asset-Based Approach to Digital Inclusion Research in the US Context”, in Ragnedda, M. and 
Mutsvairo, B. (Eds.), Digital Inclusion an international comparative analysis. Lanham, MD: Rowman \& Littlefield.

Roberts, E., Anderson, A., Skerratt. S. and Farrington, J. (2017a), “A review of the rural-digital policy agenda from a community resilience perspective", Journal of Rural Studies, Vol. 54, pp. 372-385.

Roberts, E., Beel, D., Philip, L. and Townsend, L. (2017b), "Rural resilience in a digital society: Editorial", Journal of Rural Studies, Vol. 54, pp. 355-359.

Salemink, K., Strijker, D. and Bosworth, G. (2017), "Rural development on the digital age: A systematic literature review on unequal ICT availability, adoption, and use in rural areas", Journal of Rural Studies, Vol. 54, pp. 360-371.

Simeonova, B. (2014), Knowledge Sharing and Knowledge Interaction. University of London. Simeonova, B. (2018), "Transactive memory systems and Web 2.0 in knowledge sharing: A conceptual model based on activity theory and critical realism", Information System Journal, Vol. 28 No. 4, pp. 592-611.

Taylor, D. and Packham, G. (2016), "Social Inclusion through ICT: Identifying and Overcoming Barriers to ICT Use" Strategic Change, Vol. 25 No. 1, pp. 45-60.

Torrecillas, C., Centeno, C. and Misuraca, G. (2014) Measuring the impact of einclusion intermediary actors: Characterisation and mapping of elnclusion intermediary Actors in the EU27, European Commission, JRC-IPTS Scientific and Political Report.

Tsatsou, P. (2019), "Digital inclusion of people with disabilities: a qualitative study of intradisability diversity in the digital realm”, Behaviour \& Information Technology, pp. 1-16.

Van Dijk, J.A.G.M. (2005), The Deepening Divide: Inequality in the Information Society. London: SAGE.

Vygotsky, L. (1978), Mind in society: The development of higher psychological functions. Harvard, MA: Harvard University Press.

Wagg, S., Simeonova, B. and Cooke, L. (2018), Exploring digital inclusion initiatives through the lens of Activity Theory. European Conference of Information Systems.

Wagg, S., Simeonova, B. and Cooke, L. (2020), "Digital inclusion and Women's Health and Well-Being in Rural Communities", in: Yates, S and Rice, R (Eds.), The Oxford Handbook of Digital Technology and Society, Oxford University Press, UK.

Williams, F., Philip, L., Farrington, J. and Fairhurst, G. (2016), “'Digital-by-Default' and the 'hard to reach': Exploring solutions to digital exclusion in remote rural areas", Local Economy, Vol. 31 No. 7, pp. 757-777. 
Yamagata-Lynch, L.C., (2010), Activity Systems Analysis Methods: Understanding Complex Learning Environments, New York: Springer.

Yates, S.J., Kirby, J. and Lockley, E. (2015) “'Digital-by-Default': Reinforcing exclusion through technology", In Defence of Welfare, pp. 158-161.

Zheng, Y. and Walsham, G. (2008), "Inequality of what? Social exclusion in the e-society as capability deprivation", Information Technology \& People, Vol. 21 No. 3, pp. 222-243. 


\section{Appendix 1}

\begin{tabular}{|c|c|c|c|c|}
\hline $\begin{array}{l}\text { Activity Theory } \\
\text { Element/Theme }\end{array}$ & $\begin{array}{l}\text { Factors/themes } \\
\text { emerging from } \\
\text { the data }\end{array}$ & & Second level/codes & Examples of first level short quotes \\
\hline Subject & $\begin{array}{l}\text { Policy-level } \\
\text { digital } \\
\text { inclusion } \\
\text { stakeholders }\end{array}$ & & $\begin{array}{l}\text { Government } \\
\text { departments, government } \\
\text { funded organisations, } \\
\text { national and third sector } \\
\text { organisations } \\
\text { Convenor of practice } \\
\text { Policy and practice }\end{array}$ & $\begin{array}{l}\text { 1) Policy creators, contributors, influencers } \\
\text { 2) Our role is to try to influence people/organisations to take digital inclusion more seriously and } \\
\text { to try to implement digital inclusion within their own settings } \\
\text { 2) We provide the convening and galvanizing force } \\
\text { 3) Evidence-based evaluation }\end{array}$ \\
\hline Object & $\begin{array}{l}\text { Provision of } \\
\text { digital } \\
\text { inclusion } \\
\text { initiatives }\end{array}$ & & $\begin{array}{l}\text { The reduction of } \\
\text { digitally excluded } \\
\text { individuals and } \\
\text { communities } \\
\text { Gradations of digital } \\
\text { inclusion } \\
\text { Approaches to digital } \\
\text { inclusion initiatives }\end{array}$ & $\begin{array}{l}\text { 1) Inverse Care Law - people who most need help/care are the least likely to get good access to it } \\
\text { 2) We have developed a more nuanced view of DI over the last few years } \\
\text { 3) What appeals to them and their interests, so more than just web accessibility it more about } \\
\text { relevance and compellingness. } \\
\text { 3) Case studies, evidence-based evaluation, deep-dive research }\end{array}$ \\
\hline Outcome & $\begin{array}{l}\text { Digitally } \\
\text { included } \\
\text { communities }\end{array}$ & & $\begin{array}{l}\text { Successful } \\
\text { approaches/solutions to } \\
\text { digital inclusion } \\
\text { initiatives } \\
\text { Examples of digital } \\
\text { inclusion practice } \\
\end{array}$ & $\begin{array}{l}\text { 1) Small-scale initiatives/dynamism } \\
\text { 2) Intergenerational mentoring/Digital Heroes }\end{array}$ \\
\hline Rules & Policy & & $\begin{array}{l}\text { Policy } \\
\text { Shared vision } \\
\text { Knowledge sharing } \\
\text { Lack of critical rhetoric } \\
\text { (too much 'policy } \\
\text { speak') } \\
\text { Understanding what it } \\
\text { means and takes to be } \\
\text { digitally included } \\
\text { Structures and } \\
\text { inequalities }\end{array}$ & $\begin{array}{l}\text { 1) The Essential digital skills framework is a policy stakeholder thing to make sure that we are all } \\
\text { pointing in the same direction, so we understand one another when we are debating about } \\
\text { prioritising resources for programmes } \\
\text { 2) Joined-up thinking } \\
\text { 3) One of the benefits of the network is that they have an understanding of what the local assets } \\
\text { are, and can use those assets to build relationships in order to use those assets i.e. use WIFI from } \\
\text { another organisation } \\
\text { 3) The more we can create forums to come and discuss the better. I don't think there has been } \\
\text { enough of those spaces } \\
\text { 4)Being online is not always a universal benefit. People have talked to me quite a bit about } \\
\text { people being concerned about internet addiction, cyber-bullying } \\
\text { 4) I think there is a bit of an issue with overclaiming in evaluations }\end{array}$ \\
\hline
\end{tabular}




\begin{tabular}{|c|c|c|c|}
\hline & & & $\begin{array}{l}\text { 5) When is someone digitally included? } \\
\text { 5) Libraries are a key actor, in terms of digital inclusion especially in rural communities } \\
\text { 6) Most people who don't have those complex needs and barriers are online }\end{array}$ \\
\hline Rules & $\begin{array}{l}\text { Funding \& } \\
\text { political } \\
\text { environment; } \\
\text { organisational } \\
\text { culture and } \\
\text { operational } \\
\text { practices }\end{array}$ & $\begin{array}{ll}\text { 1. } & \text { Policy \& frameworks } \\
\text { 2. } & \text { Funding models } \\
\text { 3. } & \text { Evaluation } \\
\text { 4. Investment in } \\
\text { infrastructure } \\
\text { 5. Funding cuts/austerity } \\
\text { 6. }\end{array}$ & $\begin{array}{l}\text { 1) Political will behind the issue } \\
\text { 1) Problems such as Universal Credit } \\
\text { 2) Digital inclusion funding driven by targets per head and the number of people supported. } \\
\text { 3) What works and what doesn't work } \\
\text { 3) Most evaluation that I have seen in DI has been quite home-made } \\
\text { 4) Not so many organisations are doing digital inclusion outreach work in rural areas largely } \\
\text { due to the costs of travelling and the lack of funding } \\
\text { 5) The organisations that tend to have the best ability to penetrate into hard to reach communities } \\
\text { are small local charities, but they are also the ones with the least resource } \\
\text { 5) Digital inclusion is not suitably funded and there is a lack of commitment from government } \\
\text { 5) Assets are depleting in rural areas } \\
\text { 6) There is a culture of reticence } \\
\text { 6) A lot of older people are worried about scams }\end{array}$ \\
\hline Tools & $\begin{array}{l}\text { Digital devices; } \\
\text { online learning } \\
\text { content; } \\
\text { intermediaries }\end{array}$ & $\begin{array}{ll}\text { 1. Policy } \\
\text { 2. Intermediaries } \\
\text { 3. Trusted people, trusted } \\
\text { places } \\
\text { 4. Informal learning } \\
\text { 5. Digital tools/devices } \\
\text { 6. Connectivity } \\
\text { 7. Digital skills learning } \\
\text { content } \\
\text { 8. Digital } \\
\text { understanding/competen } \\
\text { cy/literacies } \\
\text { 9. Approaches to digital } \\
\text { skills training }\end{array}$ & $\begin{array}{l}\text { 1) So much has been removed from the analogue channel that people who are [digitally] } \\
\text { excluded get a really poor service } \\
\text { 2) We work through intermediary organisations. } \\
\text { 3) Digital champions } \\
\text { 3) It's trusted people in local places who are going to help those who are not online } \\
\text { 4) It's been shown that people who are most in need of digital inclusion support and are the } \\
\text { hardest to reach are the ones who need that long-term support } \\
\text { 5) Touch-screen tablets, VR-headsets, mobile phones } \\
\text { 6) Infrastructure is difficult in rural areas } \\
\text { 7) Online or offline or blended learning content } \\
\text { 8) Information literacy, digital literacy, computer skills } \\
\text { 8) I think we have developed a more nuanced view of DI over the last few years } \\
\text { 9) Could be something like in a care home setting using VR headsets to engage people in a } \\
\text { different way, or with mental health programmes, having a look at what apps are available to get } \\
\text { people interested in digital }\end{array}$ \\
\hline Tools & $\begin{array}{l}\text { Technological } \\
\text { infrastructure }\end{array}$ & $\begin{array}{ll}\text { 1. } & \text { Broadband, mobile } \\
\text { service }\end{array}$ & $\begin{array}{l}1 \& 2) \text { Access is still an issue. Perhaps less on not having devices, more about 'not spots' rural } \\
\text { areas with poor broadband, WIFI or data limit }\end{array}$ \\
\hline Community & $\begin{array}{l}\text { Digital } \\
\text { inclusion } \\
\text { stakeholders; } \\
\text { Funders }\end{array}$ & $\begin{array}{l}\text { Policy-level } \\
\text { organisations regional } \\
\text { and local digital } \\
\text { inclusion intermediary }\end{array}$ & $\begin{array}{l}\text { 1) Community assets/Community hubs } \\
\text { 2) Government, local authorities, trust organisations } \\
\text { 3) I think where commerce and industry have a shared objective in getting people online }\end{array}$ \\
\hline
\end{tabular}




\begin{tabular}{|c|c|c|c|}
\hline & Corporates & $\begin{array}{ll}\text { organisations, tutors and } \\
\text { digital champions; and } \\
\text { recipients of digital } \\
\text { inclusion activities } \\
\text { 2. Funding } \\
\text { organisations/governmen } \\
\text { t } \\
\text { 3. IT corporations, banks, }\end{array}$ & \\
\hline $\begin{array}{l}\text { Division of } \\
\text { Labour }\end{array}$ & $\begin{array}{l}\text { UK } \\
\text { government } \\
\text { National and } \\
\text { local } \\
\text { government } \\
\text { National } \\
\text { stakeholders } \\
\text { Regional and } \\
\text { local } \\
\text { organisations }\end{array}$ & $\begin{array}{ll}\text { 1. } & \text { UK government } \\
\text { 2. } & \text { National and local } \\
\text { government (England, } \\
\text { Scotland, Wales) } \\
\text { 3. } \\
\text { 4ational Stakeholders } \\
\text { Regional \& local } \\
\text { organisations }\end{array}$ & $\begin{array}{l}\text { Hierarchical } \\
\text { Power relations } \\
\text { Reliance on intermediaries } \\
\text { Public health services, libraries, networks, local assets } \\
\text { It's the assets that we are drawing on by delivering through the network }\end{array}$ \\
\hline
\end{tabular}

